\title{
STUDIES ON MECHANICAL, WEAR AND CORROSION PROPERTIES OF AI6061-BERYL-CERIUM OXIDE HYBRID METAL MATRIX COMPOSITES
}

\author{
A.Anilkumar' ${ }^{1}$ C.Anilkumar ${ }^{2}$, H.N.Reddappa ${ }^{3}$ \\ ${ }^{1}$ Department of Mechanical Engineering, K.S.Institute of Technology, Karnataka, India \\ ${ }^{2}$ Professor, Department of Mechanical Engineering, K.S.Institute of Technology, Karnataka, India \\ ${ }^{3}$ Associate Professor, Department of Mechanical Engineering, Bangalore Institute of Technology, Karnataka, India
}

\begin{abstract}
The present work mainly investigates the wear behavior and corrosion resistance properties of Al6061/Beryl/Ceo ${ }_{2}$ hybrid metal matrix composites.Al6061/Beryl/Ce $\mathrm{O}_{2}$ hybrid MMCs containing four different wt\% $(6,8,10,12 \%)$ of beryl and keeping 0.2 wt $\%$ of cerium oxide constant have been fabricated by using a liquid metallurgy (stir casting) method. The tensile test and hardness test was done according to ASTM standards and a dry sliding wear tests were performed using a Pin-on disc wear testing machine on both composites and a matrix alloys over a load range of $4.905 \mathrm{~N}-19.62 \mathrm{~N}$, sliding velocity of $1.66 \mathrm{~m} / \mathrm{s}$ and for various sliding distance of 1-6km, finally corrosion test was done by dipping a sample in 1Molar HCL solution for a duration of 96hrs with increments of 24hrs. The hybrid metal matrix composites was characterized by scanning electron microscopy (SEM) to verify the uniform distribution of Beryl/Ceo 2 particles in Al 6061. Further it was observed from the experimental results that the specific wear rate and the corrosion of the composite decreases with the increase in Beryl/Ceo 2 particles. The best results of minimum wear rate and minimum corrosion rate was obtained at $12 \%$ weight fraction of Beryl and $02 \%$ weight fraction of Ceo 2 .
\end{abstract}

Keywords: Aluminum MMCs, Beryl, Ceo 2 , Dry sliding wear, corrosion resistance, wear resistance.

\section{INTRODUCTION}

Aluminum is one of the most popular matrix for the Metal Matrix Composites (MMCs). The Al alloy is quite attractive due to its inherent properties such as low density, their capability to be strengthened by precipitation, better wear resistance, good corrosion resistance, high thermal and electrical conductivity and their high damping capacity, also when this aluminum is reinforced with ceramic particles shows improved mechanical properties to weight ratio [1, 2].

To prepare these Al MMCs various methods have been tried and developed by the researchers, but the most industrial oriented process to fabricate MMCs is liquid metallurgy vortex route [3, 4] because of its advantages such as economical, mass production, near net shaped components can be produced [5], as compared to powder metallurgy, sintering and alloying.

Over the years aluminum based metal matrix composites are reinforced with $\mathrm{Sic}, \mathrm{Al}_{2} \mathrm{O}_{3}$ and $\mathrm{Ti}$ are extensively studied, since the reinforcing materials are harder and having high density it results in improved hardness and better wear resistance properties [6, 7], hence reinforcing aluminum with ceramic particles results in improved wear resistance properties. But one of the main disadvantage of aluminum is it undergoes different types corrosion in the marine environment [7], hence this disadvantage can be overcome by conventionally providing certain anti corrosive coatings containing chromate like zinc chromate. But since chromate is toxic and causes serious environmental hazards [8], chromium is replaced by cerium oxide which has low toxicity and abundantly available in nature $[9,10]$.

However it is observed from the literature survey that very little work is reported with beryl and cerium oxide being used as a reinforcing phase in aluminum separately $[11,12$, 13], but no work is reported on $\mathrm{Al} 6061 / \mathrm{Beryl} / \mathrm{CeO}_{2}$ hybrid metal matrix composites, hence this present work it is aimed to fabricate $\mathrm{A} 16061 / \mathrm{Beryl} / \mathrm{CeO}_{2}$ metal matrix composites by liquid metallurgy technique and to study the various properties such as ultimate tensile strength of the composite, hardness, wear resistance and corrosion resistance of the composite.

\section{EXPERIMENTAL DETAILS}

\subsection{Materials}

In the present investigation, Al6061 alloy was used as the base matrix, while the Beryl particles, which is naturally available mineral, having the formulae $\left(\mathrm{Be}_{3} \mathrm{Al}_{2}\left(\mathrm{SiO}_{3}\right)_{6}\right)$ and Cerium oxide $\left(\mathrm{CeO}_{2}\right)$ which belongs to the rare earth metals category were used as the reinforcing material. The beryl particles used were of $53-75 \mu \mathrm{m}$ size, exhibits hardness of 7.5-8.5 on Mho's scale and density of $2.6-2.8 \mathrm{~g} / \mathrm{mm}^{3}$ which is almost similar to that of Al6061 were varied from 6-12 $\mathrm{wt} \%$ was chosen as the primary reinforcement material. The cerium oxide of $20 \mu \mathrm{m}$ size kept constant at $0.2 \mathrm{wt} \%$ was chosen as the secondary reinforcements. However there are 
sufficient evidences in the literature survey that corrosion resistance and wear resistance can be improved through the addition of cerium oxide and beryl particles. Table (1) shows the chemical composition of Al6061.

Table 1: Chemical composition of Al6061 (wt \%).

\begin{tabular}{|l|l|l|l|l|l|l|l|l|l|}
\hline $\begin{array}{l}\text { Eleme } \\
\text { nt }\end{array}$ & $\mathrm{Mg}$ & $\mathrm{Si}$ & $\mathrm{Fe}$ & $\mathrm{Cu}$ & $\mathrm{Ti}$ & $\mathrm{Cr}$ & $\mathrm{Zn}$ & $\mathrm{Mn}$ & $\mathrm{Al}$ \\
\hline Wt.\% & 0.9 & $\begin{array}{l}0.7 \\
2\end{array}$ & $\begin{array}{l}0.2 \\
8\end{array}$ & $\begin{array}{l}0.2 \\
8\end{array}$ & $\begin{array}{l}0 . \\
1\end{array}$ & $\begin{array}{l}0.0 \\
7\end{array}$ & $\begin{array}{l}0.0 \\
6\end{array}$ & $\begin{array}{l}0.0 \\
4\end{array}$ & $\mathrm{Ba}$ \\
& 2 & \\
\hline
\end{tabular}

\subsection{Fabrication of Composites}

In this work liquid metallurgy technique was used to fabricate the composites, because it has certain advantages over the other process such as economical, mass production and near net shaped components can be produced, also there are plenty of evidences from the researcher's wahab et al [14], (K.R.Suresh, et al,(2002); K.G.Satyanarayana, et al, (2002); H.N.Reddappa, et al, (2010)) [15] enumerated that a stir casting process was successfully utilized for fabrication of aluminum composites reinforced with discontinuous particles.

Liquid metallurgy technique (stir casting method) is as shown in the figure 1 . In present work commercial pure Al6061 ingots, Beryl particles and cerium oxide of $99.9 \%$ purity were selected as the starting materials. About $1.5 \mathrm{~kg}$ calculated weight of A16061 ingots are taken in a graphite crucible that was inserted in an electric furnace and the temperature is set around $800 \pm 5^{\circ} \mathrm{C}$. Beryl particles which were preheated to $200^{\circ} \mathrm{C}$ and cerium oxide of $99.9 \%$ purity were added to the melt after effective degassing. Mechanical stirring of molten alloy for duration of 10-15mins was achieved by using ceramic-coated steel impeller with a speed maintained at $300 \mathrm{rpm}$. Finally the molten composite was poured in to the cast iron mould. The extent of beryl particles was varied for $6-12 \%$ whereas the cerium oxide content was kept constant at $0.2 \%$ for all the melts, then the composite was allowed to solidify naturally for duration of $24 \mathrm{hrs}$ and then component was taken out from the cast-iron mould by separating both the cope and the drag boxes.

\subsection{Experimental Work}

\subsubsection{Tensile and Hardness Test}

The cast components and pure Al6061 were machined to obtain tensile, hardness and wear specimens. The tensile test was carried according to ASTM standards B-557 on a servo controlled SHIMATZU DYNAMIC testing machine. All the specimens were loaded till fracture and the readings of ultimate tensile strength etc. were noted. Hardness tests were conducted according to ASTM standards, Brinell hardness number (BHN) has been calculated using $2.5 \mathrm{~mm}$ ball indenter. The test was done on the three different locations on the sample to negate the possibility of indenter resting on hard particles, which may give superfluous result.

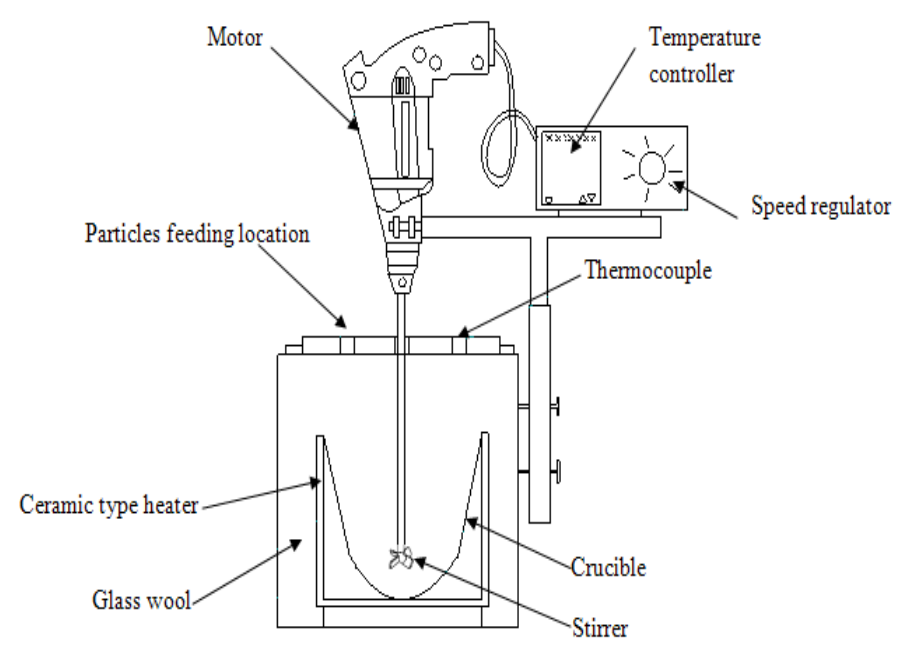

Fig 1: stir casting equipment used for fabrication of Al6061/Beryl/Cerium oxide composites.

\subsubsection{Dry Sliding Wear Test}

Wear test was carried out using a pin-on-disc apparatus (MODELL: TR20LE, WEAR AND FRICTION MONITOR, DUCOM MAKE INDIA), as per ASTM G9995 standards under varying applied load (4.905-19.62N) and a varying sliding distance (1-6KM) at a fixed sliding speed of $1.66 \mathrm{~m} / \mathrm{s}$, against EN32 steel disc of hardness 65Rc.The wear specimens are of $8 \mathrm{~mm}$ diameter and $30 \mathrm{~mm}$ length were machined from cast samples and polished metallographically. The pin samples were subjected to a four different loads $(4.905,9.81,14.715,19.62 \mathrm{~N})$ and at each load samples were subjected to a sliding distances of $1000 \mathrm{~m}-6000 \mathrm{~m}$.

The wear loss of the specimens was measured as height loss in micrometers, which was recorded by LVDT. This height loss in micrometer is converted in to volumetric loss by multiplying it by area of cross section of the pin. And finally the specific wear rate was calculated by dividing volumetric loss by normal load applied by cantilever condition and sliding distance.

\subsubsection{Corrosion Test}

Gravity weight loss corrosion test as per ASTM standards is followed in our work. Pure Al6061 and Al6061/Beryl/Ceo 2 composites were dipped in a solution of $1 \mathrm{M}$ HCL for duration of 24-96 hours. Initially before the specimen is subjected to corrosion, the initial weight of the specimen is noted and then $10 \mathrm{ml}$ of HCL is added to the $100 \mathrm{ml}$ standard flask. After transferring the $1 \mathrm{M} \mathrm{HCL}$ solution in to the standard flask the initially weighed sample is dipped in to the solution, and left for a period of 24 hours. After the time period of 24 hours specimen is taken out of the $1 \mathrm{M} \mathrm{HCL}$ solution, then it is dipped in acetone solution for 60 seconds. Then the specimen is dried and the weight of the specimen is checked after corrosion. The same procedure is repeated for every 24 hours up to 96 hours by replacing $1 \mathrm{M} \mathrm{HCL}$ solution and noting down the initial and final weight of the specimen. 


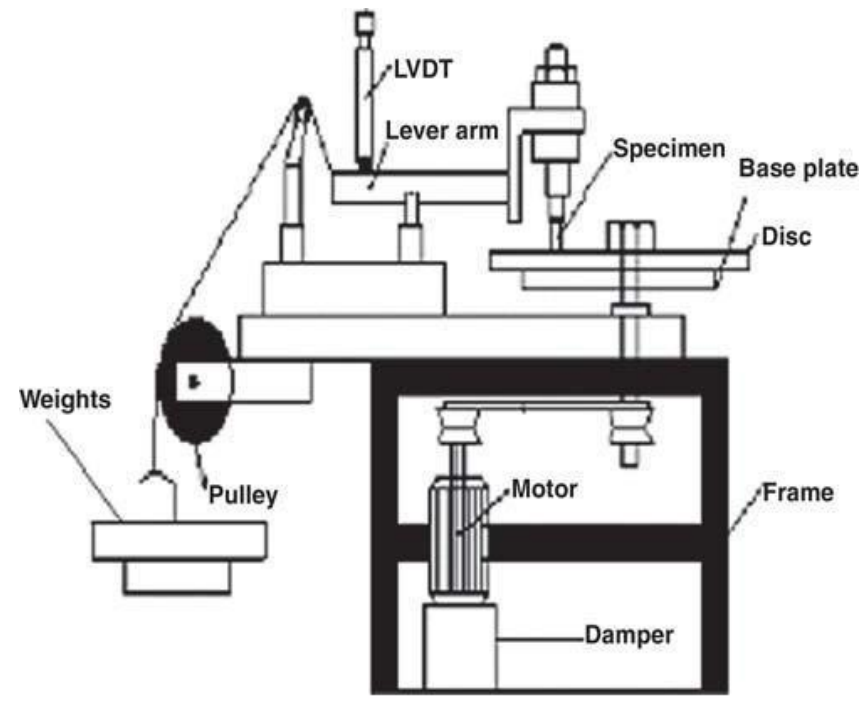

Fig 2: A 2-Dimensional view of pin-on-disc wear testing machine.

\section{RESULTS AND DISCUSSIONS}

\subsection{Microstructure Studies}

Scanning electron microscopy (SEM) images of the pure Al6061 alloy and Al6061 mixed 12\%wt of Beryl and $0.2 \%$ wt of $\mathrm{CeO}_{2}$ composite is as shown in the figures. It is clear from the SEM images that there is homogeneity in the distribution of reinforcements $\left(\mathrm{Beryl} / \mathrm{CeO}_{2}\right)$ in the matrix (Al6061) alloy, along with the evidence of minimal porosity in the composites. Also it is with excellent interface bonding exists between reinforcement and base matrix, where the reinforcements $\left(\right.$ Beryl/ $\left./ \mathrm{CeO}_{2}\right)$ are surrounded by solid solution of Al6061.

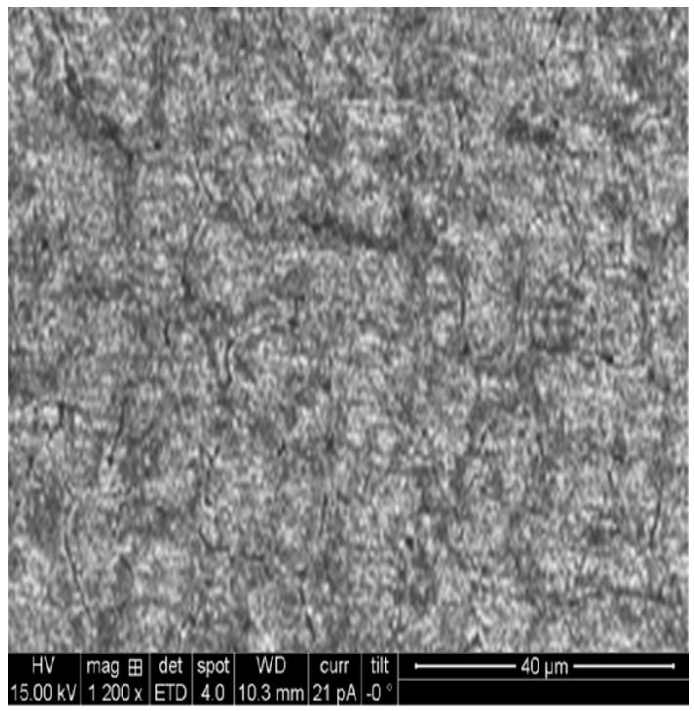

Fig 3(a): (a) Microstructure of Al6061

The above figure shows the microstructure of cast A16061, it can be observed from the microstructure that pure Al6061 and $\mathrm{Al} 6061 / \mathrm{Beryl} / \mathrm{CeO}_{2}$ hybrid metal matrix composites have been prepared with minimum porosity.

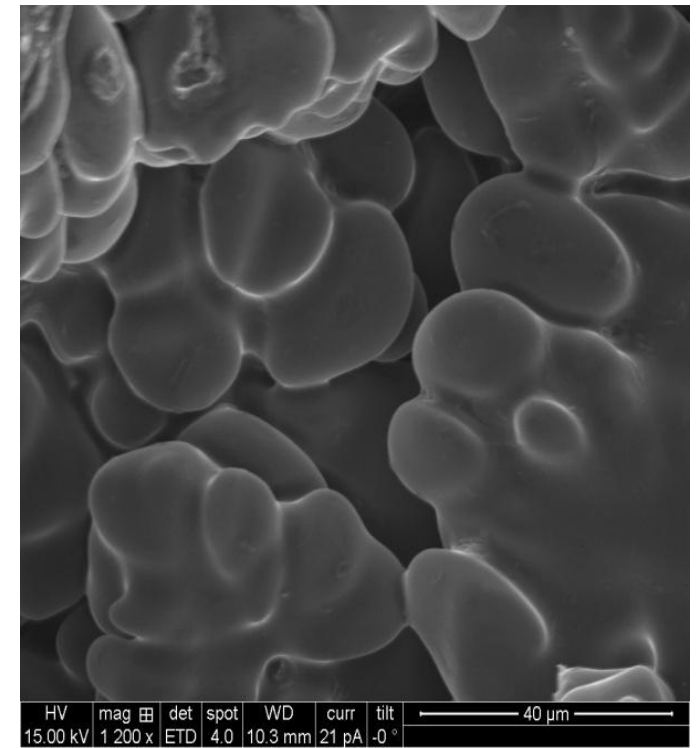

Fig 3 (b): Microstructure showing Al6061/ $\mathrm{CeO}_{2}$ composites.

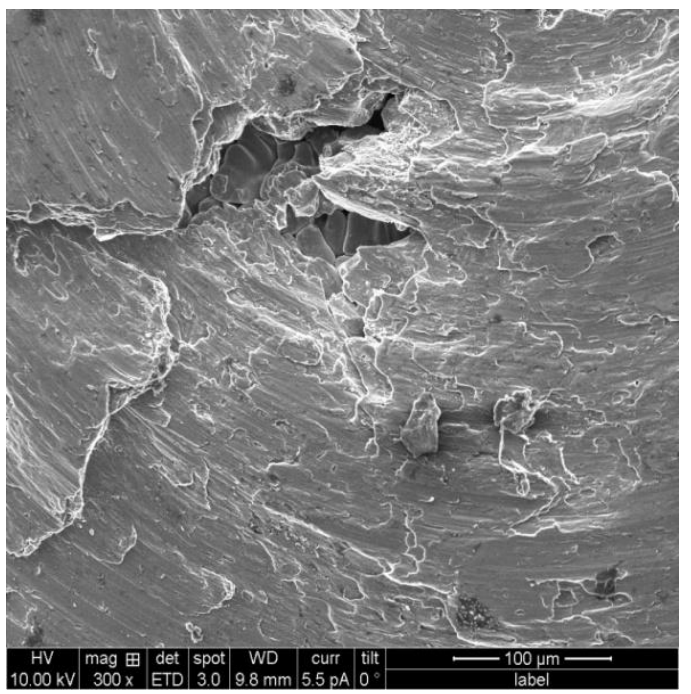

Fig 3 (c): Microstructure showing Al6061/Beryl Composites.

\subsection{Tensile and Hardness Test}

The tensile properties of the $\mathrm{Al} 6061 / \mathrm{Beryl} / \mathrm{CeO}_{2}$ composites have been evaluated and it is compared with that of Al6061 matrix material. It is clear from the figure (4) that addition of Beryl $/ \mathrm{CeO}_{2}$ actually enhances the tensile strength. However best results observed is for $12 \%$ wt of beryl and $0.2 \%$ wt of $\mathrm{CeO}_{2}$. The increase in tensile properties may be attributed to the following three parameters.

(a) The presence of harder Beryl and $\mathrm{CeO}_{2}$ particles (Oxide Particle).

(b) Due to the addition of these reinforcements may have given rise to large residual compressive stress, developed during the solidification of composites, due to difference in coefficient of expansion between ductile matrix and brittle ceramic particles [16-20].

(c) Due to the closer packing of reinforcements and hence smaller intermolecular spacing. 
Table 2: Tabulated Test results of Tensile Test.

\begin{tabular}{|l|l|l|}
\hline SI NO. & COMPOSITION & UTS (mpa) \\
\hline 1. & Al6061 & 76.4 \\
\hline 2. & Al6061+6\%Beryl+0.2\% $\mathrm{CeO}_{2}$ & 95.748 \\
\hline 3. & Al6061+8\%Beryl+0.2\% $\mathrm{CeO}_{2}$ & 104.5 \\
\hline 4. & Al6061+10\%Beryl+0.2\% $\mathrm{CeO}_{2}$ & 114.5 \\
\hline 5. & Al6061+12\%Beryl+0.2\% $\mathrm{CeO}_{2}$ & 118.162 \\
\hline
\end{tabular}

\section{Hardness:}

The hardness of the composites increases with the increase in the Beryl/ $\mathrm{CeO}_{2}$ concentration, this is because since the Beryl/ $/ \mathrm{CeO}_{2}$ particles being harder than Al6061 alloy they render hardness to the matrix [21].

Also hardness varies linearly. The composites with $12 \%$ wt of Beryl and $0.2 \%$ wt of $\mathrm{CeO}_{2}$ show the best results, as shown in figure (5).

Table 3: Tabulated Test results of Hardness Test.

\begin{tabular}{|l|l|l|}
\hline SI.NO. & COMPOSITION & BHN \\
\hline 1. & Al6061 & 60.2 \\
\hline 2. & Al6061+6\%BERYL+0.2\%CeO & 71.6 \\
\hline 3. & Al6061+8\%BERYL+0.2\% $\mathrm{CeO}_{2}$ & 75.7 \\
\hline 4. & Al6061+10\%BERYL+0.2\% $\mathrm{CeO}_{2}$ & 79 \\
\hline 5. & Al6061+12\%BERYL+0.2\% $\mathrm{CeO}_{2}$ & 80.1 \\
\hline
\end{tabular}

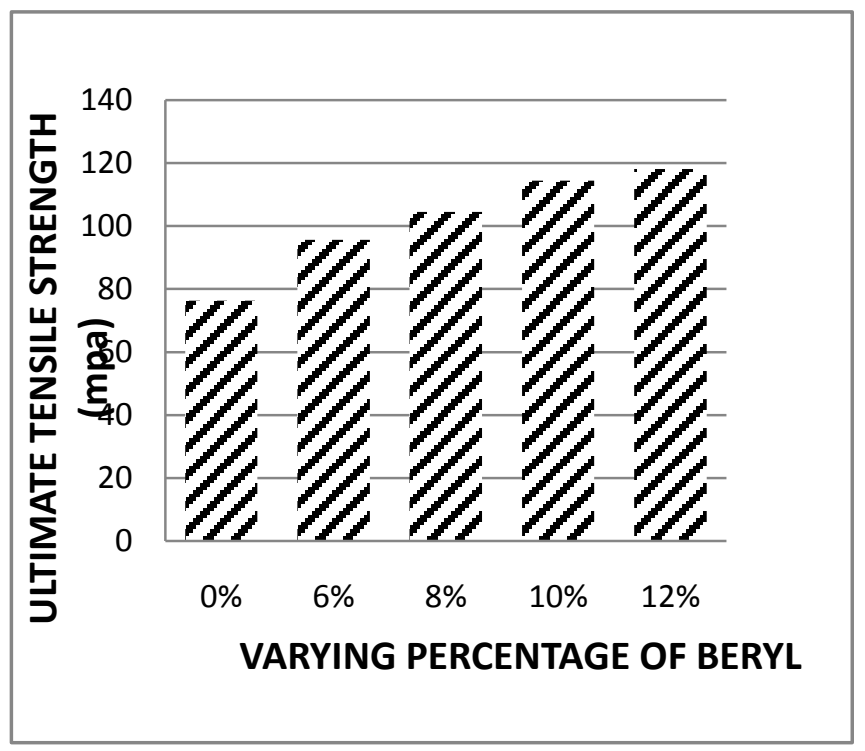

Fig 4: Ultimate tensile strength of Al6061/Beryl/Ceo 2 composites.

\subsection{Dry Sliding Wear}

Figures 6 and 7 shows the specific wear rate as the function of load and sliding distance. The specific wear rate of pure Al6061 and four different wt $\%$ of beryl $/ \mathrm{CeO}_{2}$ are as shown in the following figures.

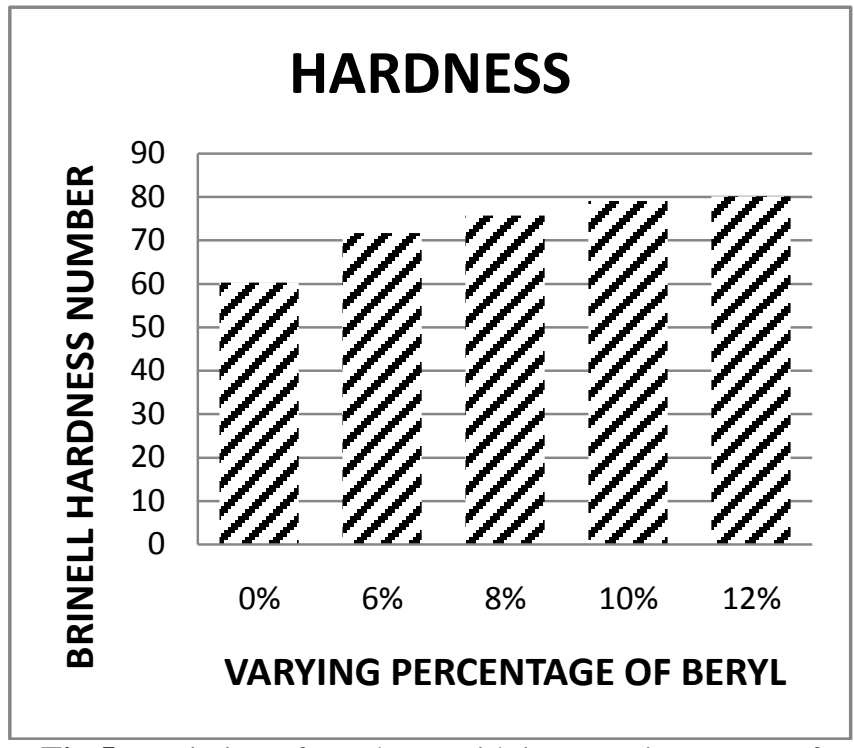

Fig 5: Variation of Hardness with increase in content of oxides $\left(\right.$ Beryl $\left./ \mathrm{CeO}_{2}\right)$.

Figure 6 indicates that specific wear rate decrease with the increase in the load for all the materials, which indicates the improved wear resistance at higher loads. Figure 7 depicts the plots of specific wear rate for pure Al 6061alloy and Al6061/Beryl/ $\mathrm{CeO}_{2}$ composites for different sliding distances (1000-6000m). It can be observed from the figures that specific wear rate decrease with increase in quantity of beryl and sliding distance. The decreasing trend of wear rate with increasing sliding distance may be due to the face that initially the asperities on the surface of the pin and disc come in contact with each other, during initial period they get fractured and results in high wear rate, as the sliding continues surface becomes more and more plane and wear gets neutralizes. The graphs exhibit two regions which may be called as 'running-in' and 'steady state' periods.

During the running-in period, the wear rate increases very rapidly with increasing sliding distance. During the steady state period, the wear progressed at a slower rate [22].

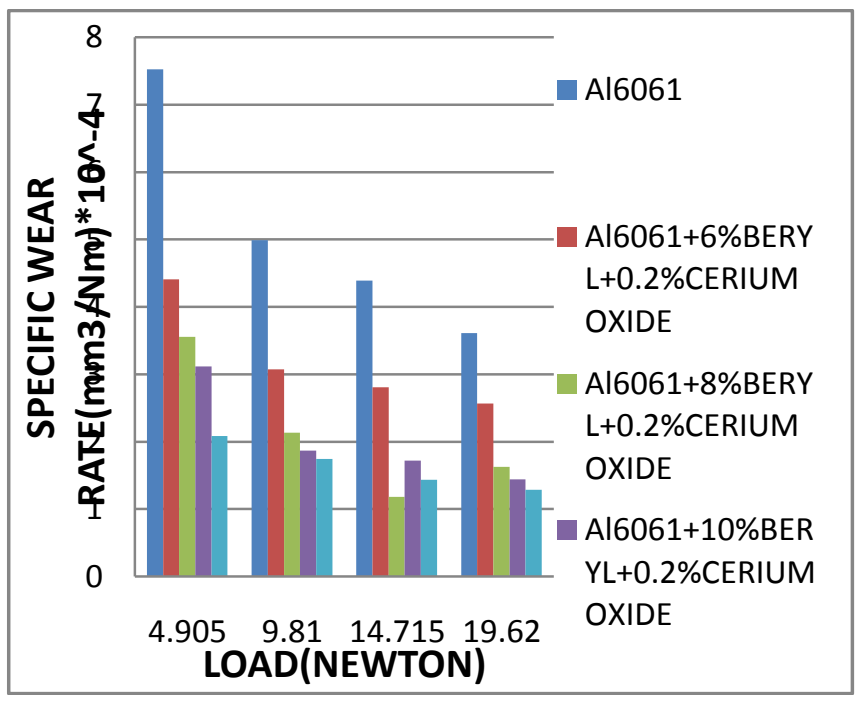

Fig6: Specific Wear rate as a function of load. 


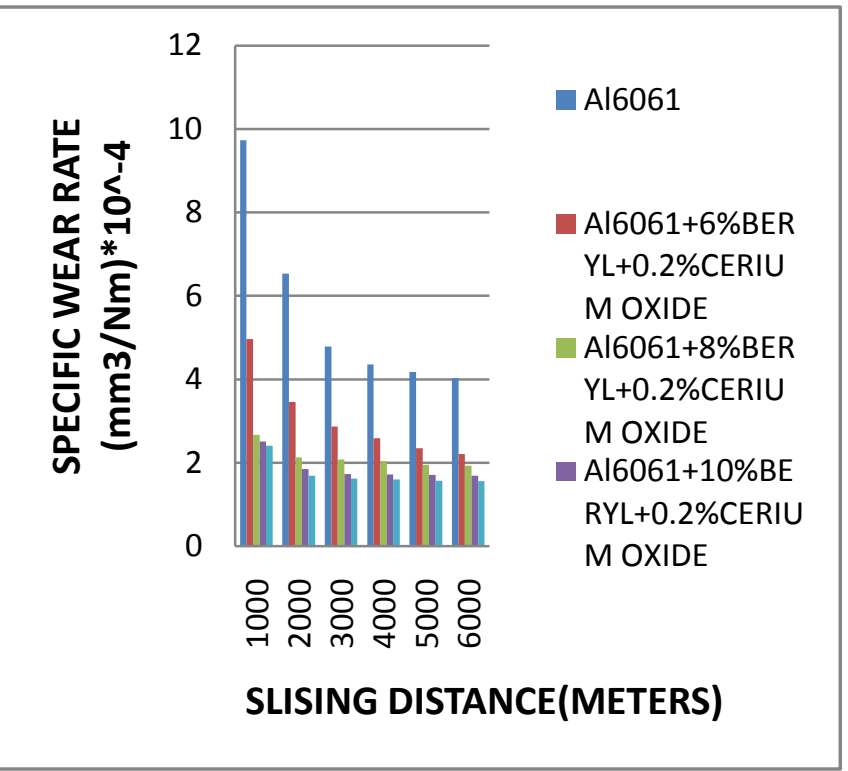

Fig 7: Specific Wear rate as a function of sliding distance.

\subsubsection{Frictional Force Studies}

The variation of frictional force as a function of load and sliding distance is as shown in fig8 and fig9. Following inference can be drawn by looking at the trend of the plots. From the analysis of figure 8 it can be concluded that the increase of the load leads to a significant increase of the co efficient of friction. According to the Bowden and Tabor theory (Bowden, F.P (1986)), effects of the normal and tangential loads were considered separately. It was considered that the normal load determined the real area of contact, and to shear over this area, tangential force was needed. If the normal load is increased, then the real area of contact will increase along with tangential force. Hence, instantaneous value of coefficient of friction will also increase.

The effect of the increase in sliding distance leads to a marginal decrease of the co efficient of friction for fixed load and percentage of Beryl/ $\mathrm{CeO}_{2}$, shown in Figure9. During the initial stages, the surfaces of both the composite specimens and the steel counterpart were rough and thus strong 'interlocking' took place, resulting in a high friction coefficient. As the wear process continued, the rough profiles of the steel rotating disc and the composite specimens were smoothened as a result of abrasion and a transfer film formed. The fluctuations in the coefficient of friction may be due to variation in contact between sample and disk. Composites have shown lower coefficient of friction in comparison to pure aluminum for longer sliding distances.

\subsubsection{Worn Surface Morphology}

Fig 10. (a) and (b) shows the SEM images of Al6061/12\%wt Beryl/ $/ 2 \% \mathrm{CeO}_{2}$ composites and pure Al6061 material. Figures clearly depicts that the composites exhibits much rougher surface than that of the Al6061 alloy, this can be attributed to the fact that addition of cerium oxide results in formation of protective layer on the surface of the Al6061 material and also the fact that the ceramic particles were found inside the cavities indicates that some particles were broken and pulled out from the surface. This suggests an abrasive wear mechanism, which is essentially due to exposure of hard ceramic particles on the worn surface and loose fragments between two surfaces. As the ceramic particles resist the delamination process, the wear resistance is more in the case of composites alloy [12].

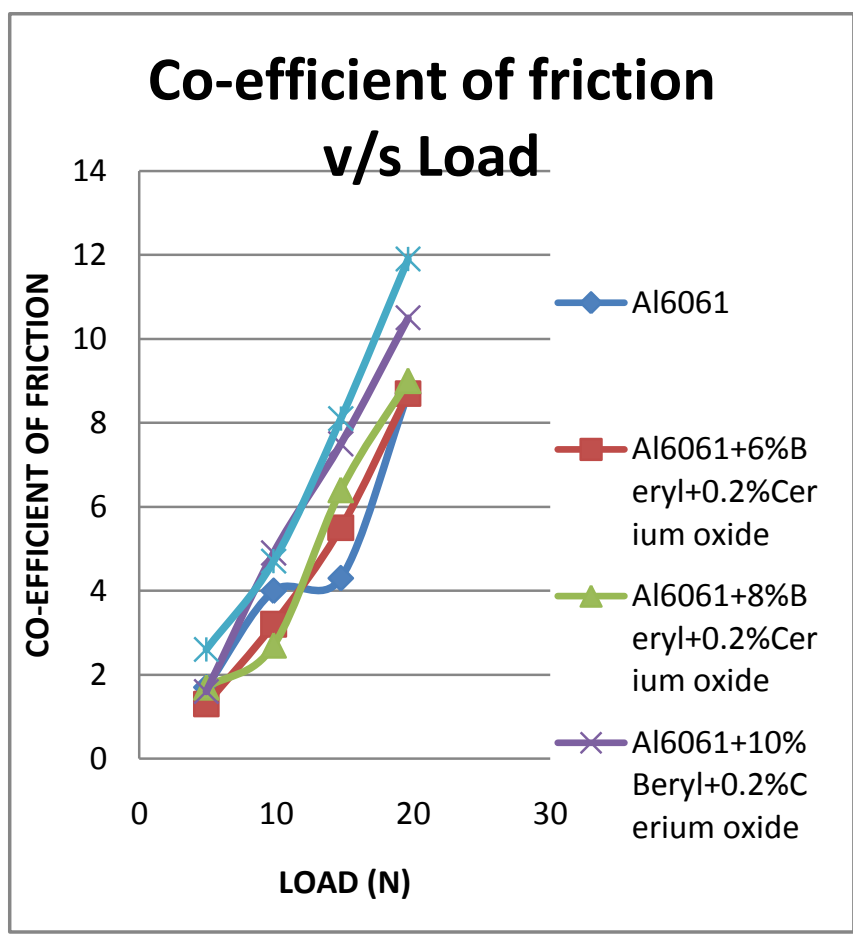

Fig 8: Co-Efficient of friction as a function of load

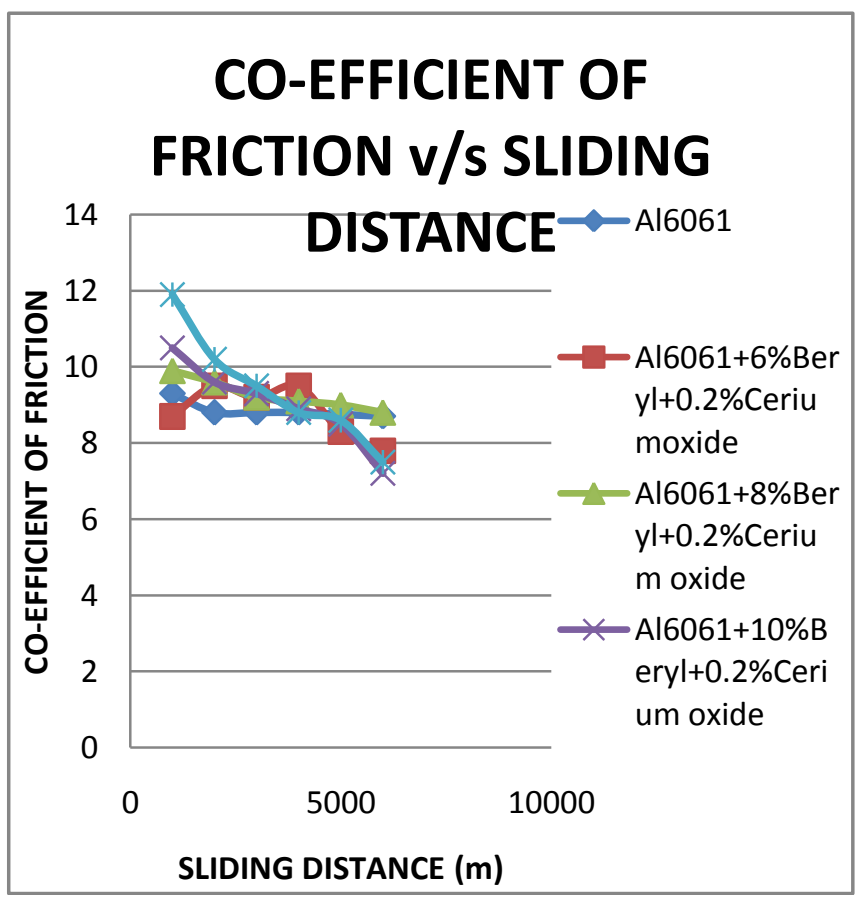

Fig 10: Co-efficient of friction as a function of sliding distance 


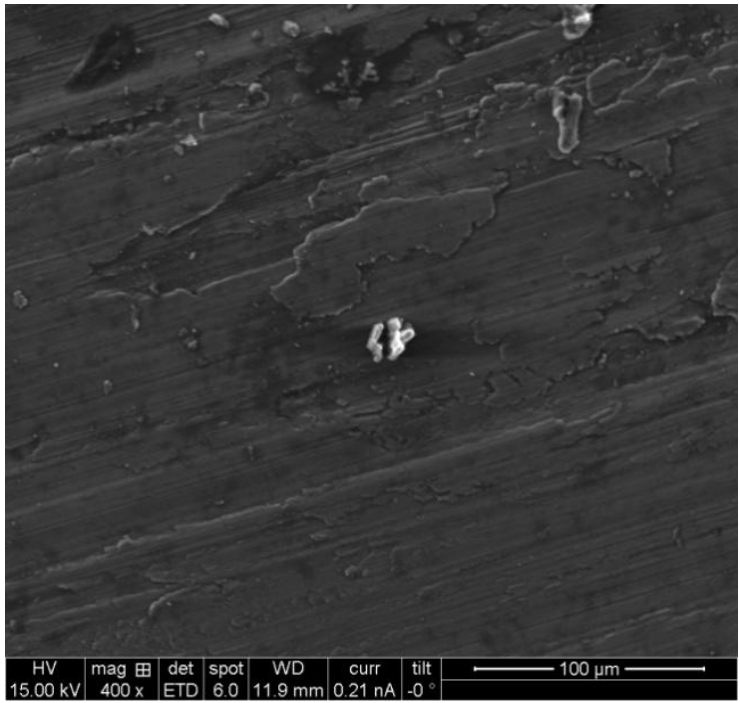

(a)

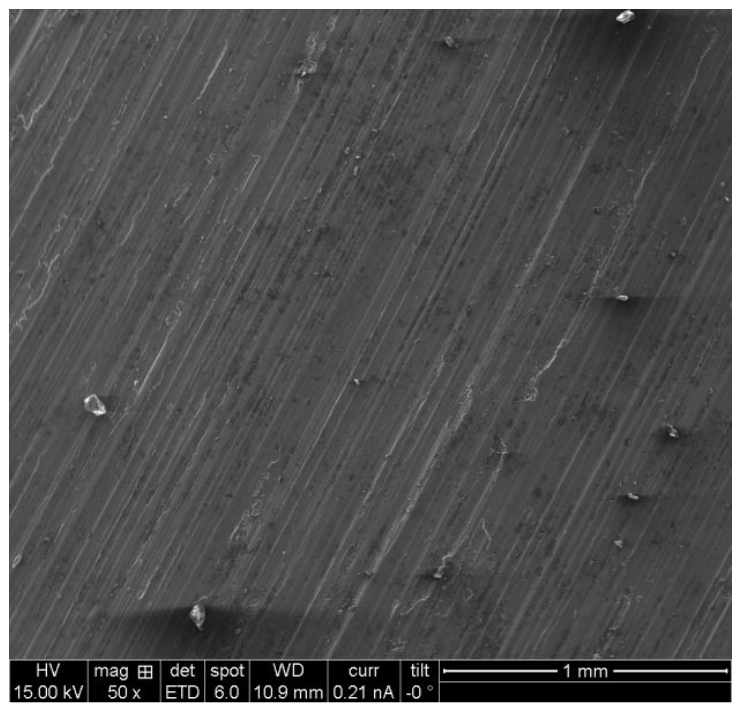

(b)

Fig 10: shows the worn surfaces of (a) Al6061/12\%Beryl/0.2\% $\mathrm{Ceo}_{2}$, (b) Pure Al6061

\subsection{Corrosion Test}

Corrosion test results are as shown in the figure 11 ; it can be seen from the figure that corrosion resistance increases with the increase in oxide content (Beryl/cerium oxide), this can be attributed to the fact that oxides being anti-corrosive nature they corrode very less in corrosive environment, hence composites with higher oxide content corrodes less. Also fact that cerium oxide is used during the fabrication of composites, which helps to form the protective layer on the Al6061 material which ultimately helps to suppress the corrosion, the present results lay strong emphasis on the potential scope of use of $\mathrm{CeO}_{2}$ for protection of aluminum in marine environments $[9,10]$.

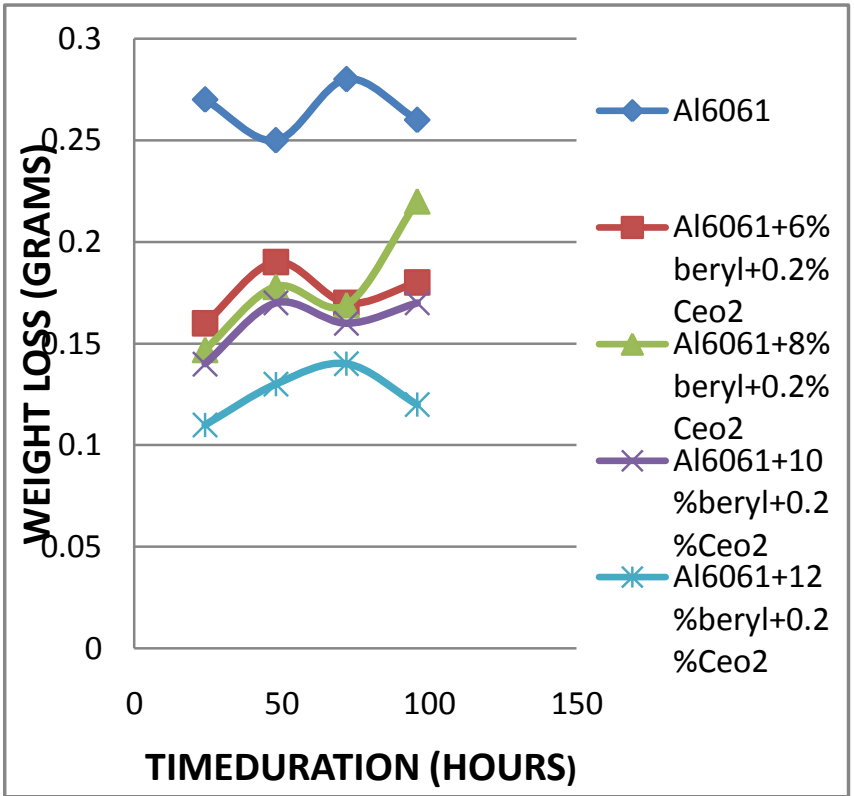

Fig 11: Corrosion behavior of Al6061 \& Al6061/Beryl/CeO 2 Hybrid MMCs.

\section{CONCLUSIONS}

The following conclusions can be drawn from the present work

- $\quad \mathrm{Al6061/Beryl} / \mathrm{Ceo}_{2}$ composites have been success fully fabricated by using liquid metallurgy technique (stir casting).

- Composites with $12 \%$ wt beryl and $0.2 \%$ cerium oxide shows increase in the tensile properties and hardness properties which substantially higher than Al6061 alloy.

- Dry sliding wear test was performed and composites with $12 \%$ wt and $0.2 \%$ cerium oxide performs excellently and wear was approximately $7.4 \%$ lesser than that of the base alloy, further increase in the oxide content will result in further increase in mechanical and wear properties but not in proportionate to the extent of reinforcement.

- The corrosion of aluminum in marine environment can be suppressed substantially by the addition of cerium oxide, composites prepared with $0.2 \%$ of cerium oxide and $12 \%$ of beryl performed excellently.

- On a final note one of the highlights of this work is, both wear and corrosion properties have been evaluated and tried a very rare combination of Al6061+Beryl+Ceriumoxide composites.

\section{REFERENCES}

[1] K. R. Suresh, H. B. Niranjan, P. Martin Jabraj and M. P. Chowdaiah, "Tensile and Wear Properties of Aluminum Composites," Wear, Vol. 255, No. 1-6, 2003. pp. 638-642.

[2] D. M. Taylor, "Metals Hand Book," ASM, Materials Park, 1982, pp. 859-863.

[3] K. Sukumaran, K.K. Ravikumar, S.G.K.Pillai, T.P.D.Ranjan, M.Ravi, R.M.Pillai, B.C. Pai, 
Materials Science and Engineering: A, Volume 490, Issue 1-2, 25 August 2008, PP. 235-241.

[4] M. Kok, Journal of Materials Processing Technology, Volume 161, Issue3, 30 April 2005, PP. 381-387.

[5] C. S. Ramesh, "Processing and Characterization of Metal Matrix Composites," Proceedings of the National Seminar on Recent Trends in Liquid Crystals, Polymer, and Composite Materials, Ramanagaram, 2003, pp. 10-13.

[6] Sunny Chung, Bing H. Hwang, Tribology International, Volume27, Issue5, October1994, PP. 307-314.

[7] Z. Szklarska-Smialowska, Corr. Sci. 41 (1999), pp: $1743-1767$.

[8] M. Bettencourt, F.J. Botana, J.J. Calvino, M. Marcos, M.A.Rodriguez-Chacon, Corros. Sci. 40 (1998), PP. 1803-1819.

[9] M.A. Arenas, M. Bettencourt, F.J. Botana, J. de Damborenea, M.Marcos, Corros. Sci. 43 (2001), PP.157-170.

[10] M.A. Arenas, M. Bettencourt, F.J. Botana, J. de Damborenea, M.Marcos, Corros. Sci. 43 (2001), PP.157-170.

[11] Reddappa.H.N, Suresh.K.R, Niranjan.H.B, Satyanarayana.K.G, "Dry sliding friction and wear behavior of Aluminum/Beryl composites", vol2, no2, 2011.

[12] P.MuhamedAshraf, S.M.S.Shibli, "Reinforcing aluminum with cerium oxide: A new and effective technique to prevent corrosion in marine environments", 26, August, PP.443-448.

[13] A.S.Anasyida, A.R.Daud, M.J.Ghazali. "Dry sliding wear behavior of Al-4si-4mg Alloys by addition of cerium", vol4 (2009), No.2, 127-130.

[14] M. N. Wahab, A. R. Daud and M. J. Ghazali: Preparation and Characterization of stir castAluminum nitride reinforced Aluminum Metal matrix: International Journal of Mechanical and Materials Engineering (IJMME), Vol. 4 (2009), No. 2, 115-117.

[15] K.R. Suresh, et al., Dry sliding wear of Al 356beryl metal matrix composite, in: Proceedings of the Third Australasian Conference on Composite Materials (ACCM-3), 15-18 July 2002,Auckland, New Zealand.

[16] A. B. Gurcan and T. N. Baker, "Wear," Elsevier Sequoia, Lausanne, 1995, pp. 185-191.

[17] R. Higgins, "Engineering Metallurgy," Krieger Publishing Company, Melbourne, 1983, pp. 181.

[18] A. Flinn and P. D. Trojan, "Engineering Materials and Their Applications," 4th Edition, Jaico Pub. House, Bom- bay, 1993, pp. 650.

[19] G. E Dieter, "Mechanical Metallurgy," 2nd Edition, Mc- Graw-Hill, Kongakusha, 1981, pp. 221.

[20] R. J. Arenault and R. M. Fischer, "Microstructure of Fiber and Particulate SiC in 6061 Al Composites," Scripta Metallurgical, Vol. 17, No. 1, 1983, pp. 6771.

[21] D. L. McDanieal, "Analysis of Stress-Strain, Fracture and Ductility Behavior of Al MMCs Containing
Discontinuous Silicon Carbide Reinforcement," Metallurgical and Materials Transactions A, Vol. 16, No. 6, 1985, pp. 1105- 1113.

[22] J. ZHANG and A. T. ALPASt: Actu material; Transition between mild and sever wear in Aluminum alloys: Vol.45, No. 2, 1997 pp. 513-528. 